2

\title{
Integriranje dohodkov v kmečki ekonomiji v zgodnjem novem veku: historiografski pregled po slovenskih pokrajinah
}

\author{
Ines Beguš \\ Goriški muzej \\ Grajska cesta 1, 5000 Nova Gorica \\ ines.begus@goriskimuzej.si \\ Fakulteta za humanistične študije \\ Univerza na Primorskem \\ Titov trg 5, 6000 Koper \\ ines.begus@fhs.upr.si
}

\section{Uvod}

Poseganje kmečkega prebivalstva $\mathrm{v}$ neagrarne dejavnosti je bilo $\mathrm{v}$ slovenskem prostoru precej razširjeno. Že v zgodnjem novem veku se je namreč velik del slovenskega agrarnega prebivalstva s svojimi pridelki, izdelki in storitvami vključeval v lokalne in čezmejne trge ter trgovske tokove na krajše in daljše razdalje. Zametki znanstvenega preučevanja tega pomembnega dela agrarne zgodovine se umeščajo $\mathrm{v}$ čas raziskovanja mestnega oz. neagrarnega gospodarstva v prvi polovici 20. stoletja (Gestrin 1982b, 205), ko je bilo aktualno obravnavanje »boja« meščanstva proti podeželski trgovini (na primer Zwitter 1929; Žontar 1939, ponovna izdaja 1982). Poglobljenejše raziskave na temo kmečke trgovine in tovorništva $\mathrm{v}$ slovenskem prostoru je v slovenskem zgodovinopisju prispeval Gestrin v šestdesetih letih prejšnjega stoletja. Vzporedno z njegovimi raziskavami so nastajala še druga dela, ki posredno obravnavajo tudi »dopolnilne« dejavnosti kmečkega prebivalstva. Tu mislimo predvsem na dela na temo lokalne zgodovine, študije drugih področij slovenske zgodovine in na splošne zgodovinske preglede v obliki enciklopedičnih izdaj (na primer Blaznik 1973; Grafenauer 1962; Blaznik idr. 1970; 1980; Čepič in Nećak 1979). V zadnjem času je opaziti ponoven interes za raziskovanje tega dela agrarne zgodovine, ki se ga raziskovalci lotevajo $\mathrm{z}$ novimi metodološkimi pristopi in primerjalnimi analizami $\mathrm{z}$ alpskim in zahodnoevropskim prostorom (Panjek 2011; 2014; 2015a; 2017). 
$\mathrm{V}$ tem prispevku obravnavamo prisotnost neagrarnih dejavnosti na slovenskem podeželju na podlagi zgodovinarske literature. $\mathrm{V}$ ta namen so najprej predstavljene nekatere osnovne poteze in problemski pristopi zgodovinarskih obravnav, za prikaz njihovih izsledkov in ugotovitev, s katerim smo želeli izpostaviti izrazito raznolikost dejavnosti, ki jih izpričujejo številni članki in knjige, pa smo imeli na voljo več poti, pri čemer smo se odločali predvsem med dvema: predstavitev po panogah ali na regionalni osnovi. Odločili smo se za slednjo, ker ob upoštevanju sektorske pripadnosti in ohranjanju poudarka na pestrem naboru kmečkih neagrarnih dejavnosti, značilnem za slovensko podeželje, omogoča hkraten vpogled $\mathrm{v}$ lokalne specifike in primere specializacije, ki so pomemben element za poznavanje in interpretacijo praks integriranja dohodkov med kmečkim prebivalstvom.

\section{Uvod v slovensko zgodovinopisje o kmečki trgovini in drugih neagrarnih dejavnostih}

Kot prvega, ki v svojem delu opisuje gospodarske dejavnosti, s katerimi se je kmečko prebivalstvo ukvarjalo v novem veku, lahko štejemo kranjskega plemiča Janeza Vajkarda Valvasorja. V svojem obsežnem delu Slava vojvodine Kranjske iz leta 1689 je temeljito popisal in raziskal naravne, zgodovinske in kulturne elemente v posameznih regijah takratne Kranjske. Med drugim je v svoje opise zajel tudi aktivnosti, s katerimi so kmetje integrirali svoje vire dohodka. Ti opisi so še danes pomemben vir preučevanja v slovenski zgodovini in jih bomo kasneje tudi natančneje predstavili.

Temeljne študije o zgodovini neagrarnih dejavnosti kmečkega prebivalstva ter »zgodnjem kapitalizmu« na Slovenskem je opravil Ferdo Gestrin.' V okviru preučevanja gospodarstva in družbe v slovenskih deželah v zgodnjem novem veku se je v svojih delih posvetil trgovini, naložbam trgovskega - predvsem tujega - kapitala, trgovskim izmenjavam med slovenskimi zalednimi in primorskimi mesti, vrstam trgovskega blaga in trgovskim potem, ki so že v novem veku povezovale slovenske dežele z Jadranom in alpskim prostorom ter ogrskimi in italijanskimi deželami. Precejšen poudarek je namenil tistemu delu trgovske dejavnosti, ki je bil v domeni agrarnega prebivalstva, to je kmečki trgovini z lastnimi ali tujimi pridelki in izdelki, tovorništvu in tihotapstvu. Za kmečko oz. podeželsko

Glej Gestrinova dela 1962; 1963; 1965; 1972; 1973a; 1973b; 1973c; 1973d; 1982a; 1982b; $1991 \mathrm{idr}$. 
trgovino in tovorniško dejavnost je kot prvi tudi definiral terminologijo, ob njem pa velja na to temo omeniti še Šorna. ${ }^{2}$

Razvoj kmečke trgovine od 13. stoletja do začetka novega veka je Gestrin opredelil v dveh časovnih obdobjih, ki sovpadata $\mathrm{z}$ obdobji prodiranja blagovno-denarnih odnosov na zemljiško gospostvo in ju označuje kot prva in druga stopnja komercializacije zemljiškega gospostva. V prvem obdobju, ki traja od 13. do sredine 14. stoletja, je z uveljavitvijo denarnih dajatev "proces komercializacije precej na široko odprl vrata v okvire zemljiških gospostev in dobil mnogo širše družbene osnove. Zato so v trgovino posegajoči podložniki začeli kmalu prebijati meje veljavne družbene delitve dela « (Gestrin 1973b, 45-6) z vedno bolj razširjenim trgovanjem mimo mest in trgov, kar je pričelo ustvarjati trenja med mesti in vasjo. V drugi polovici 15. stoletja je po mnenju Gestrina zaznati nove razvojne težnje. Podeželska trgovina je v tem obdobju, ki ga označuje druga stopnja komercializacije zemljiškega gospostva, prehajala v svoj »višek« (Gestrin 1973a, 74; 1973b, 45). Prisotnost blagovno-denarnega gospodarstva $v$ zemljiškem gospostvu je bila po njegovem že tako velika, da je vplivala na odnose v celotni fevdalni družbi. Posledice so se kazale v spremembi strukture zemljiškega gospostva in njegovi vedno večji komercializaciji. Fevdalci so izhod iz »krize zemljiškega gospostva« iskali na različne načine. Med drugim so pričeli izrazito posegati $\mathrm{v}$ blagovno-denarne odnose, pri čemer so kmete vključevali v trgovske posle, uvajali določbe, da lahko kmetje prodajajo pridelke in izdelke samo njim in si s tem lastili kmečko trgovino ter nalagali podložnikom obveznost tlačnega tovorništva in prodaje gospodovega blaga (Gestrin 1973a, 74; 1991, 224-6, 235). Zahteve fevdalcev so sicer omejevale trgovanje kmetov $\mathrm{z}$ lastnimi pridelki in blagom, a kljub temu se je kmečka trgovina že zelo razmahnila tudi $\mathrm{z}$ vključevanjem kmetov $\mathrm{v}$ trgovino meščanov. Razlogov za poseganje kmečkega prebivalstva v trgovsko dejavnost je bilo po mnenju Gestrina več. Prvi je bil potreba, ki je izvirala iz teženj zemljiških gospodov po odplačevanju fevdalne rente v denarju ter večanju davčnih bremen s strani deželne uprave in države. Poleg tega vidi dodaten razlog v majhnosti kmetij, katerih donosnost ni zadostovala za poplačilo naraščajočih davkov in fevdalne rente (Gestrin 1991, 248). Vendar majhnost kmetij in nuja po dodatnem viru dohodka v denarju po Gestrinovem mnenju nista bila edina vzroka za širjenje kmečke trgovine. $\mathrm{V}$ poseganju kmetov $\mathrm{v}$ trgovsko dejavnost vidi tudi željo po pridobivanju

2 Gestrin 1973a, 73; Gestrin 1982a, 347; Šorn 1984, 43; o terminološkem vprašanju glej prispevek A. Panjeka v tej knjigi. 
denarja in trgovsko podjetnost kmetov - temu vidiku je več pozornosti namenjene v prvem poglavju, zato ga tu le omenjamo. Kot smo že omenili, je poseganje kmečkega prebivalstva $\mathrm{v}$ trgovino in širjenje blagovno-denarnih odnosov po Gestrinovem mnenju pričelo načenjati takratno družbeno delitev dela, kar pa se ni kazalo samo v odnosih znotraj zemljiških gospostev, torej med fevdalcem in podložnikom, temveč tudi med mestom in podeželjem (Gestrin 1973a, 74-5). Ta tematika je bila v slovenskem zgodovinopisju pogosto obravnavna, in sicer kot boj meščanstva proti podeželski trgovini oz. kot boj za podeželsko trgovino med mestom in vasjo. Temeljni vir avtorjem pri preučevanju tega vprašanja so bili predlogi in sprejeti akti policijskih redov za dolnjeavstrijske dežele iz prve polovice 16. stoletja, ki jih je kot prvi prevedel in objavil Josip Žontar. ${ }^{3}$ Kot je razvidno iz njihove vsebine, se je pri sestavi aktov deželni knez opiral na deželne stanove, ki so bili zlasti predstavniki plemstva in zemljiških gospodov, in na predstavnike mest slovenskih dežel.

Meščanstvo si je prizadevalo omejiti oz. odpraviti poseganje kmečkega prebivalstva $\mathrm{v}$ trgovsko dejavnost, ki naj bi bila v domeni mest. Vendar so bili podložniki pri tem deležni podpore deželnih stanov, ki so zagovarjali njihovo poseganje po dopolnilnih dejavnosti, saj naj bi s tem lažje odplačevali fevdalna bremena. Tu se razkrije dvojna vloga plemstva $v$ odnosu do podložnika. Po eni strani so predstavniki zemljiških gospodov podpirali poseganje kmečkega prebivalstva $\mathrm{v}$ podeželsko trgovino, kot zaznamo tudi že iz obravnave Gestrina (1991, 251), po drugi strani pa so težili k povečanju »fevdalnega izkoriščanja do skrajnosti« in monopolu presežkov kmečke proizvodnje. Mestom je v tem boju sprva uspelo omejiti podeželsko trgovino. Že leta 1525 so koroška mesta predlagala, da se duhovščina, plemstvo in kmetje ne bi smeli ukvarjati »s prekupčevanjem, ker se jim ne spodobi. Saj morejo živeti duhovniki in plemiči od svojih rent in dednih dohodkov, kmetje pa so preskrbljeni s hrano od letnih plodov« (Žontar 1956-57, 47). Tudi v kasnejših predlogih iz leta 1542 najdemo zahteve, naj "noben duhovnik, plemič, meščan in kmet« ne trgujejo ali prekupčujejo z blagom, kmečko trgovino pa naj bi se omejilo le na prodajo lastnih presežkov na sejmih v mestih in trgih. Deželni stanovi se s takimi določbami niso strinjali in sčasoma dosegli, da so dežele prejele nekatere olajšave v prid podeželske trgovine, ter s tem vsaj navidezno stopili tudi v bran svojim podložnikom.

3 Žontar 1956-57. Obravnave boja mest in vasi na podlagi omenjenega vira sicer zasledimo že ob koncu 19. in v začetku 20. stoletja (Vrhovec 1886; Zwitter 1929). Za nadaljnje analize in povzetke teh dokumentov glej na primer Grafenauer (1962), Gestrin (1991, 191; 1973a, 72) idr. 
Na stanovskih deželnih zborih so kot razlog, da kmetje ne morejo odplačevati davkov, navedli, da se "revnim ljudem " preprečuje vsako kupčevanje; »brez njega pa se pri svojih drobnih, malo rodovitnih 'gruntih' ne morejo prehraniti in vzdrževati. Ako nimajo kmečki podložniki zaslužka, zemljiški gospod ne more dobiti dajatev in davkov« (Žontar 1956-57, 73). Tudi leta 1552 so zatrjevali, da se kmetje ne bi mogli obdržati na kmetijah, če se ne bi ukvarjali s tovorništvom na Goriško, Vipavsko, v Trst in na Laško ter tam trgovali ter da posebej na Dolenjskem in na Krasu kmetje ne bi zmogli ostati na svojih kmetijah, če ne bi trgovali in bili dejavni v prevozništvu (Žontar 1956-57, 114).

Žontarja je sicer v obravnavanih virih bolj kot težnje mest po odpravi podeželske trgovine zanimalo, kakšne so bile gospodarske in družbene spremembe po posameznih slovenskih pokrajinah na prehodu iz srednjega v novi vek. Zanj najpomembnejša ugotovitev, ki so mu jo posredovali policijski redovi, je diferenciacija v vseh slojih prebivalstva. Pri kmečkemu sloju je zasledil delno gospodarsko in ne toliko družbeno rast. Zaradi višanja dajatev, davkov in drugih pristojbin se je položaj nekaterih pravih kmečkih gospodarstev nekoliko poslabšal. Kljub temu je na podeželju zaznati kmete, ki so imeli tudi po tri kmetije. Bistveno je narasel sloj kajžarjev, to je kmetov z malo zemlje, ki se je pretežno vključeval v platnarstvo ter trgovino z živino in platnom. Tretjo plast kmečkega prebivalstva so tvorili gostači, ki svoje zemlje niso imeli in so se preživljali pretežno kot dninarji.

$\mathrm{Z}$ analizo in objavo policijskih redov je dal Žontar pomemben prispevek tako k spoznavanju razmerij med različnimi družbenimi sloji takratnega prebivalstva kot tudi poznavanju vzrokov, obsega in raznolikosti neagrarnih dejavnosti kmetov. Kasnejšim avtorjem, med katere spada tudi že predstavljeni Gestrin, je s tem dal kar nekaj izhodišč, ki so jim bila v pomoč pri razvijanju interpretacij o pomenu neagrarnih virov dohodka za kmečko prebivalstvo in položaju kmečkega prebivalstva na Slovenskem v zgodnjem novem veku.

Položaju kmečkega prebivalstva $\mathrm{v}$ 16. stoletju in pomenu neagrarnih dejavnost se je v svojih delih posvetil tudi Bogo Grafenauer. Tudi njega so zanimali vzroki in položaj kmečke trgovine in obrti v času razvoja mestnega gospodarstva $v$ novem veku ter boj meščanstva proti podeželski trgovini. Po njegovem mnenju vzrokov za dvig kmečke trgovine ne gre iskati samo $\mathrm{v}$ majhnosti kmečkih obratov, $\mathrm{v}$ katerih kmetje niso uspeli pridelati zadostne količine hrane, temveč tudi $v$ mestni omejitvi maksimalnih odkupnih cen poljskih pridelkov, po katerih so plačevali kmetom. Zatem so 
meščani žito prodajali naprej po bistveno višji ceni in na ta način zadržali zase velik del dobička. Temu so se kmetje želeli izogniti in žito prodajati drugje, kjer bi lahko dosegli višje prodajne cene (Grafenauer 1962, 61-2). Te ugotovitve je Grafenauer kasneje v svojem raziskovalnem delu integriral s študijami kmečkih uporov na Slovenskem. Pri obravnavi vzrokov kmečkih uporov izpostavlja omejevanje kmečkega trgovanja s strani meščanstva in zemljiških gospodov - kot ga obravnavata tudi Gestrin in Žontar - ter deželnega kneza. V programih kmetov je namreč jasno zaznati, da je $\mathrm{v}$ kmečko trgovino posegala tudi država $\mathrm{z}$ vedno strožjim mitninskim in cestnim režimom. Med pritožbami in zahtevami kmetov v kmečkih uporih je bilo pogosto izraženo nezadovoljstvo $\mathrm{z}$ uveljavljanjem prisilnih poti in novih mitnic ter uveljavljanjem in večanjem mitnin, ki jih je odrejala država. Konjiški kmetje so na primer v kmečkem uporu leta 1514 v eni od dvanajstih točk oz. zahtev, namenjenih cesarju, navedli, da jih na raznih krajih »obtežujejo z nenavadnimi cestami (pač glede obvezne poti pri kmečkem trgovanju!), ki jih po starem nikoli ni bilo in ki bi jih tudi radi naznanili« (Grafenauer 1974, 6o-1). V programu hrvaško-slovenskega kmečkega upora leta 1572/73 Grafenauer ugotavlja, da je imelo podeželsko trgovanje že izjemno velik pomen med vzroki za upor. Argumenti pa so bili tudi tokrat nove oz. zvišane mitnine in carine, ki so bremenile trgovanje kmeta v slovenskih deželah (Grafenauer 1974, 155-6).

Po mnenju Grafenauerja je pot do uporov odprl tedanji gospodarski razvoj v smeri zgodnjega kapitalizma, ki je deloval »na osebni položaj podložnikov v smislu sprostitve ter s tem zaostril družbena nasprotja « ${ }^{4}$ (1973, 27). Iskanje virov dohodka tudi zunaj zemljiškoposestnih razmerij, bodisi $\mathrm{v}$ trgovini in tovorništvu bodisi $\mathrm{v}$ fužinarstvu, podeželskem obrtništvu ali založniških razmerjih, je po njegovem mnenju spodbudilo mobilnost kmečkega prebivalstva, ki naj bi bila do tedaj precej omejena s strani deželnega plemstva. »Posebno tovorništvo je čedalje bolj odpiralo podložnikom in njihovim sinovom vrata $\mathrm{v}$ poslovno življenje in v svet, kamor ni segala moč njihovih zemljiških gospodov« (Grafenauer 1973, 27), medtem ko je trgovina znatno »vplivala na notranje razslojevanje vaškega prebivalstva«. Predvsem na Kranjskem se je posebej hitro večal sloj kajžarjev, ki zaradi majhnih zemljiških posesti »niso mogli živeti brez vaške obrti, prometa in trgovine, zlasti pa ne brez zaslužka v zvezi s fužinarstvom« (Grafenauer 
1974, 133-4). Istočasno se je na podeželju razvijala sicer manj številčna skupina kmetov, ki je s trgovanjem pridobila precejšnje premoženje in se $\mathrm{z}$ odkupovanjem zemljišč osvobodila dolžnosti, ki so jih vezale na zemljiškega gospoda, kot ugotavlja tudi Žontar.

$\mathrm{V}$ zadnjih letih se temi neagrarnih virov dohodka $\mathrm{z}$ novimi pristopi in raziskovalnimi vprašanji posveča Aleksander Panjek. Ugotoviti skuša vzroke za poseganje kmetov po neagrarnih virih dohodka, pri čemer izhaja iz tu že obravnavanih značilnosti kmečke ekonomije na Slovenskem. Pri svojih obravnavah je prišel do dveh ključnih ugotovitev. Pri prvi pritrjuje interpretacijam Gestrina in Grafenauerja, da se je kmečko prebivalstvo vključevalo v neagrarne dejavnosti iz potrebe, saj mu je to omogočalo doseganje ravni preživetja in sposobnost plačevanja davkov. Vendar po Panjekovem mnenju to še ni pomenilo, da je pri tej potrebi šlo tudi za pasivno sprejeto rešitev. Razdrobljenost in majhnost kmetij, ki niso uspele zagotoviti preživetja samo s kmetijsko dejavnostjo, kažeta na to, da je lahko podeželsko prebivalstvo tudi računalo na možnost dostopa do alternativnih dejavnosti.

Sčasoma je postal pojav drobitve in razslojevanja prebivalstva posledica obstoječih neagrarnih virov dohodka ter neagrarnih dejavnosti, zaradi česar so si kmetje lahko privoščili živeti na manjših kmetijskih obratih, ki jim sicer niso omogočali samozadostne oskrbe (Panjek 2015a, 202; Panjek 2017, 15, 22-3). Druga ugotovitev ravno tako izhaja iz slovenskega zgodovinopisja, ki ugotavlja, da je znotraj sicer precej razslojenega kmečkega prebivalstva poleg kmetov $\mathrm{z}$ malo ali nič zemlje obstajal tudi delež premožnejših in podjetnejših kmetov, ki so ravno tako posegali po neagrarnih dejavnostih. To dokazuje, da se teh dejavnosti niso posluževali samo najrevnejši sloji kmečkega prebivalstva za doseganje ravni preživetja, ampak tudi bogati kmetje, katerih cilj ni bil preživetje, temveč želja po izboljšanju življenjskega statusa in podjetniška sposobnost. Na podlagi teh interpretacij Panjek razvija koncept integrirane kmečke ekonomije kot sistem, za katerega je značilno integriranje kmečkih in neagrarnih virov dohodka iz primarnega, sekundarnega ter terciarnega sektorja (Panjek 2017).

\section{Pregled po deželah in pokrajinah osrednje in zahodne Slovenije}

Poglejmo si bolj podrobneje gospodarske dejavnosti, s katerimi je slovensko kmečko prebivalstvo integriralo svoje dohodke od kmetijstva. Pred tem je potrebno dati nekaj pojasnil o tem, katera območja in panoge niso 
bile vključene v analizo in zakaj. Najprej gre za številčnost zgodovinopisnih del, ki omenjajo kombiniranje kmetijstva z neagrarnimi panogami. Čeprav se, z izjemo zgoraj obravnavanih avtorjev, ostalo slovensko zgodovinopisje ni posebej posvetilo tu obravnavani tematiki, je v številnih delih mogoče zaslediti neposredne omembe posameznih neagrarnih panog, v katere so se vključevali kmetje. Zato je razumljivo, da ni bilo mogoče zajeti čisto vseh avtorjev, ki so kdajkoli omenjali kmetijsko dejavnost v kombinaciji neagrarno. Prav tako ni bilo mogoče obravnavati vseh neagrarnih dejavnosti, ki jih je bilo v novem veku izredno veliko, zato so v nadaljevanju obravnavane pretežno tiste, ki so bile na določenem območju posebej razširjene in uveljavljene. Tretje pojasnilo se nanaša na omembe obrtnikov ali nosilcev drugih dejavnosti (mlinar, sodar, fužinar), za katere ni vedno jasno, ali gre za specializirane poklice ali za podložnike, ki so kmetijsko dejavnost kombinirali $\mathrm{z}$ neagrarno. Taki primeri zato $\mathrm{v}$ prispevku tudi niso obravnavani. $\mathrm{V}$ analizo je vključena približno polovica današnje Slovenije, in sicer osrednje in zahodne slovenske dežele in pokrajine, to so Kranjska (brez današnjega hrvaškega dela Istre), Goriška grofija in podeželsko območje severnoistrskih obmorskih mest, izpuščeni pa bodo deželi Koroška in Štajerska ter Prekmurje, ki je v novem veku spadalo pod Ogrsko kraljestvo. Te vzhodne regije bi zaslužile enako pozornost kot ostale, vendar bodo zaradi preobširnosti dejavnosti v ostalih deželah in omejenosti z obsegom tega prispevka tokrat izpuščene. Opuščena bo tudi predstavitev zahodnih območij s slovenskim prebivalstvom zunaj današnjih meja (tedaj Beneška republika) ${ }^{\text {s. }}$

\subsection{Gorenjska}

Začnimo pri Gorenjski, kjer so bile dejavnosti kmetov, s katerimi so integrirali svoje dohodke od kmetijske dejavnosti, precej raznovrstne. Poglejmo, kako to deželo in njene ljudi opisuje Valvasor v 17. stoletju. Med prebivalci omenja veliko tovornikov, »ki s konji tovorijo blago tja in spet sem; pa tudi veliko rudarjev ter tudi veliko tkalcev in trgovcev, ki z vsemi mogočimi deli skrbijo za svoje preživljanje in posel«. V vasi Bitnje so večinoma živeli »izdelovalci sit, ki pletejo mreže za sita iz žime [...] ti isti kmetje pa redijo tudi veliko lepih konj, ki jih večinoma vodijo na pašo v Italijo in tam prodajo«. V skoraj vsaki gorenjski vasi so za prodajo izdelovali tudi mezlan (tkanina iz lanene osnove in volne), kupčevali so $\mathrm{z}$ volno in ovčjimi siri, s črnim in rdečim usnjem ter celo s škorpijoni, iz katerih so v lekarnah izdelovapodjetne vaške skupnosti v Nadiških dolinah«. 
li škorpijonovo olje. Kot pomembni gospodarski panogi Valvasor omenja tudi pridobivanje in predelavo železa. V Bohinjski Bistrici je zabeležil prisotnost »številnih rudarjev, ki kopljejo železovo rudo, ali kako drugače najdejo svoje preživljanje v rudarski dejavnosti« (Valvasor 2009-13, 110, 117-8).

Železarstvo oz. kovaštvo se je na območju Gorenjske razvilo že v srednjem veku. Kmetje so sprva sami pridobivali in talili rudo, iz katere so nato izdelovali izdelke za svojo porabo (Blaznik 1959, 93; Mohorič 1955, 25-6; Gašperšič 1959, 5). S priseljevanjem fužinarjev in kovačev iz bližnjih dežel (Koroške in Furlanije) se je iz domače obrti pridobivanja železa pričelo razvijati bolj modernizirano fužinarstvo. Ponekod so imeli fužinarji »več hub zemlje s pašniki in planinami, kjer so pridobivali živež za fužinarsko naselje rudarjev, talilcev in kovačev, ter gozdove, kjer so žgali oglje in jemali jamski les" (Mohorič 1969, 30). V Železnikih so fužine zaposlovale kmete in dninarje kot rudoslede, kopače rude, oglarje, tovornike in delavce v obratih (Mohorič 1954, 96; Blaznik 1973, 88; Mohorič 1969, 39). Razvoj fužinarstva je v 16. stoletju na nekaterih območjih Gorenjske povzročil tudi hiter porast kajžarskega in gostaškega prebivalstva. Gašperšič omenja, da naj bi bil prav razcvet fužin pod Jelovico, v Kropi in Kamni Gorici poglavitni vzrok za nastanek kajžarstva in bajtarstva na tem območju (Gašperšič 1959, 98). Na fužinskih območjih so kajžarji delovali zlasti kot fužinski delavci ali oglarji, mnogi drugi pa so se ukvarjali tudi z obrtjo, s podeželsko trgovino in tovorništvom (Blaznik 1973, 201).

Poleg fužinarstva je bilo na tem območju precej razširjeno platnarstvo, kot omenja tudi že Valvasor. Trgovina s platnom je bila precej živahna že v 15. stoletju, posluževali pa so se je tako njeni glavni proizvajalci - kmetje kot tudi poklicni trgovci. V 16. stoletju so se v vaseh okoli Kranja že uveljavili založniški odnosi v platnarstvu pa tudi sitarstvu in železarstvu (Žontar 1982, 161), v 18. stoletju pa naj bi bili po pisanju Žontarja v loškem gospostvu že »skoraj vsi kmetje producenti platna, saj je imela skoraj vsaka hiša statve«, zelo prisoten pa je bil tudi že založniški sistem produkcije nogavičarstva (Gestrin 1965, 194; Žontar 1956; Blaznik 1973, 289; Šorn 1984, 87-8, 98; Čepič in Nećak 1979, 339).

$\mathrm{Na}$ Gorenjskem velja poleg naštetih podeželskih obrti omeniti še krojaštvo, tesarstvo, zidarstvo, sodarstvo, gostilničarstvo in mlinarstvo, ki so bile v glavnem $\mathrm{v}$ domeni kajžarskega in gostaškega prebivalstva (Blaznik 1973, 280-4; Hodnik 1995a 34, 36; Mihelič 1999, 659). Močno se je razvilo tudi tovorništvo, toda, kot navaja Valenčič, je to »tovorništvo imelo drugačen značaj, služilo je predvsem prodaji izdelkov tamkajšnjega železarstva 
in platnarstva. Deloma je bilo tudi v zvezi s kmečko trgovino. Tovorniki železnih izdelkov v Trst in Italijo so se vračali s tovori vina, gotovo ne le za lastne potrebe, temveč za prodajo « (Valenčič 1981, 251). Ena pomembnih prometnih povezav, ki so se je posluževali, je vodila preko Škofje Loke čez Poljansko dolino, mimo mitninske postaje v Bači proti Čedadu in naprej v Furlanijo v Beneški republiki ${ }^{6}$. Po tej poti je »silno cvetelo" tudi tihotapstvo (Blaznik 1973, 224). V Gorico in furlanska mesta so vozili platno, vino in živino. Slednjo so kupovali na Ogrskem, jo vzredili na svojih kmetijah in jo nato prodajali preko Tolminske v Beneško republiko (Blaznik 1973, 223; Gašperšič 1960, 152; Gestrin 1965). Nezanemarljiva je bila tudi tovorniška dejavnost, ki so jo podložniki opravljali za potrebe fužin.?

\subsection{Goriška grofija}

Pomaknimo se proti Goriški grofiji, obmejni regiji z Beneško republiko. Integrirani kmečki ekonomiji na tem območju se je v slovenskem zgodovinopisju posvetil predvsem Panjek. S prometnega vidika sta po njegovem mnenju Zgornje Posočje in Kanalska dolina predstavljala osrednji prehod čez alpsko gorovje med srednjeevropskim in sredozemskim prostorom v najvzhodnejšem delu Alp (Panjek 2002a, 217). Po bovški poti, ki je iz Furlanske nižine in doline Soče vodila prek Kobarida v Bovec in dalje čez Predel proti Trbižu na Koroškem, so bovški in tolminski kmetje prevažali vino, živino, mesne izdelke in sir. Bili so tudi glavni oskrbovalci mesta Gorice, svoje izdelke in živino pa so prodajali tudi čez mejo v beneški Čedad.

Panjek izpostavlja vino kot »bogastvo Goriške grofije« (2015b, 60), katerega glavno tržišče je bila Koroška. Vinska trgovina s Koroško je temeljila na vrsti sporazumov, po katerih so Korošci morali primarno odkupovati goriška in tržaška vina. Na Koroško so sladka goriška in tržaška vina (rebula, prosek) dobavljali preko koroških prevoznikov, krčmarjev, trgovcev, a tudi lokalnih tovornikov - slednji so bili pretežno kmečkega porekla. Med Koroško in Goriško je potekala tudi izmenjava vina za železo (Panjek 2015b, 59-79; Gomiršek 2007, 59). Poleg tega je 17. stoletju čez Kanalsko dolino

6 Več o tej prometni povezavi in drugih zvezah glej na primer v Blaznik 1966, Rajšp 1994.

7 S fužinarstvom so bili tesno povezani na primer tovorniki, ki so v Železnike prevažali rudo in oglje, iz Železnikov pa fužinarske izdelke (Blaznik 1973, 180). Fužine izpod Jelovice so svoje izdelke največ tovorile čez Bačo proti Gorici, Devinu in Vidmu ali čez Col proti Trstu in Reki. V glavnem so tod tovorili kmečki tovorniki in fužinarji (Šmitek 1989, 27, 30). 
v Goriška brda in Furlanijo prihajalo "veliko število Korošcev" na sezonsko delo, da bi se »v tamkajšnjih vinogradih začasno zaposlilo pri trgatvi« (Panjek 2002a, 218; Panjek 2015b, 102-3).

$\mathrm{Na}$ območjih Goriške, Tolminske in spodnje Vipavske doline je prebivalstvo posebej intenzivno izkoriščalo gozdne vire. Gorica se je zaradi plavljenja lesa po Soči v 16. stoletju razvila v središče lesne industrije (Gestrin 1965, 195). Kmetje so gozdove primarno izkoriščali za pridobivanje lesa in prosto pašo živine. $V$ višjih alpskih legah je potreba po lesu nastajala predvsem zaradi izgradnje staj za živino na planinah ter pridobivanja kurjave za predelovanje mlečnih izdelkov. Tudi na planotah Trnovskega gozda so bližnji podložniki in kajžarji izkoriščali cesarske gozdove za pašo ovac in koz ter košnjo. V vasi Lokve so se poleg paše ukvarjali tudi s poklici, vezanimi na gozdarstvo, kot so sekači, oglarji, tesarji in vozniki. Tu se je v 18. stoletju razvila steklarska obrt, pri kateri so sodelovali tudi domačini, ter škafarstvo, s katerim so se ukvarjali pretežno moški v zimskem času (Kolenc 2011, 97-9; 2012, 131). Gozdni les so domačini izkoriščali tudi za potrebe domače industrije. Iz njega so izdelovali kmetijska orodja in opremo tako za domačo uporabo kot prodajo v obliki suhorobarstva (Panjek 2015b, 107). Porabnik lesa goriških in posoških gozdov so bile poleg glažut fužine, ki so delovale na Bovškem, Ajdovščini in v Idriji. Izrazito razvita je bila na obravnavanem območju lesna trgovina, vezana predvsem na mesta Videm, Gorica in Trst. Prebivalci Trnovskega gozda so kot kmetje-gozdarji znaten del dohodka pridobivali s sečnjo, prevozom (furmanstvo) ter prodajo lesa v Gorico (Panjek 2015b, 110-1; Kolenc 2012, 206).

Kot industrijska dejavnost se je na Goriškem precej razvilo svilarstvo, za katero je bil les pomemben energijski vir in je nase vezalo dejavnosti, ki so se pretežno nahajale na podeželju v obliki založništva (Panjek 2015a, 1035). Gojenje sviloprejk je v 18. stoletju postalo "poleg vinogradništva važna panoga kmetijstva na Gradiščanskem in v delu Goriške«, bilo pa je v domeni pretežno »revnih prebivalcev vasi« (Žontar 1957, 16). Listje murv, s katerimi so hranili sviloprejke, so kmetje sprva kupovali in se za nakup močno zadolževali. Zato je država spodbujala zemljiške gospode, da kmetom narekujejo in omogočajo sajenje murv na njihovih zemljiščih, sama pa je kmete oproščala dajatev od te dejavnosti ter jim obljubljala nagrade. Prepoved grofa Attemsa v Sv. Križu iz leta 1768, da podložniki pošiljajo svoje otroke na delo $v$ goriške delavnice, kaže na to, da so $v$ svilarskih predilnicah delali tudi otroci kmečkega prebivalstva (Žontar 1957, 54-5, 70, 76), sicer pa je delo $\mathrm{v}$ predilnicah slonelo predvsem na tujih mojstrih-svilarjih. 
Dejavnost, ki je bila na tem območju precej razširjena, je bilo tudi tihotapstvo. To je bilo po mnenju Panjeka »sestavni del prometa in vsesplošen pojav«. Posebej živahno je bilo čezmejno tihotapstvo živine. Kako je potekalo, je razvidno iz spomenice kranjskih mest iz leta 1548:

Ko peljejo konja na Laško, mu naložijo majhen tovor, kakor da bi hoteli iti po vino ali sol. [...] Ko pa dospejo na Beneško, prodajo konja s tovorom vred. [...] V bližini beneške meje dajo kmetom zemljiški gospodje za denar dovolilnice, kakor da bi šlo za hišne potrebe. Tako priženo kmetje vole in drobnico, ne da bi plačali mitnino, ponoči pa tihotapijo živino preko gora na Beneško. Blaga, ki ga prineso kmetje $v$ zameno iz Benečije, ne prodajajo samo $v$ deželi pri svojih domovih in neposredno pred mestnimi vrati, marveč ga tovorijo dalje $v$ tretjo ali četrto deželo. (Žontar $1956-7,85)^{8}$

Za tihotapljenje je veljalo tudi izogibanje predpisanim trgovskim potem, s čimer so se tovorniki izmikali plačilu mitnin in carin. Iz Kranjske prek Vipavske doline in Krasa na Goriško ter s Krasa v Tržič (na beneškem ozemlju) so na ta način tihotapili vino, žito in živino. Skozi Posočje, čez bohinjske gore proti Kobaridu in z Bovškega so tihotapili predvsem mast, sir in v veliki meri že omenjeno živino. $\mathrm{V}$ večini primerov je bila končni cilj Beneška republika (Panjek 2002a, 221-2; Panjek 2015b, 102).

$\mathrm{Na}$ Goriškem je potrebno kot pomemben vir dohodka kmečkega prebivalstva posebej izpostaviti rudnik živega srebra v Idriji, ki je bil v novem veku največji rudnik živega srebra na svetu za španskim Almadnom. Rudnik je kmečke sinove zaposloval v obliki mezdnega in pogodbenega dela kot kopalce in žgalce rude ter črpalce vode iz rudnika (Verbič 1952$3,534,538)$. Transport so opravljali idrijski podložniki ter podložniki sosednjih gospostev, predvsem loškega (Verbič 1963, 98). Glavni izdelovalec in dobavitelj lončenih posod za taljenje rude so bili $\mathrm{v}$ prvih dveh stoletjih delovanja rudnika kmečki lončarji z območja Škofje Loke. Posode so izdelovali izključno za potrebe rudnika, kar nakazuje že na industrijsko proizvodnjo oz. obliko založništva (Verbič 1963, 99; Blaznik 1973, 222; Kavčič 2010, 144; Panjek 2015b, 108). Očitno neizogibno je bilo tudi tihotapstvo z živosrebrno rudo, ki so se ga posluževali pretežno podložni-

8 Podobno izkoriščanje dovolilnic za čezmejno prodajo je v arhivskih virih zasledil tudi Panjek s strani bovških podložnikov (Panjek 2000, 162; 2002b, 221). 
ki-kramarji idrijskega, tolminskega in loškega gospostva, ki so v Idrijo prihajali pod pretvezo, da prinašajo živež v zameno za čipke, ki so jih nakupovali od idrijskih klekljaric. Tradicija izdelovanja idrijskih čipk, ki so se ga posluževale kmečke žene in dekleta, sega že v 16. stoletje. Laneni sukanec in platno so v zameno za čipke nabavljale v Škofji Loki (Verbič 1969, 157; Hodnik 1995a, 1995b; Terpin 2007, 84).

\subsection{Notranjska, Vipavska dolina in Kras}

Z vzhoda je v Gorico in dalje v beneško Furlansko nižino vodila cesta čez Vipavsko dolino in Notranjsko, ki je prihajala s Kranjske. Na Notranjskem so se odcepile še druge poti, ki so čez Kras vodile proti obalnim mestom Trst, Štivan, Koper, Izola, Piran ter Reka. Poglejmo kako je območje Notranjske, Vipavske doline in Krasa opisal Valvasor. Na Krasu, kjer je "zemlja kamnita«, kjer "primanjkuje lesa in vode in kjer "nimajo nobenega žita in jedo zelo suh kruh«, vendar pa zori "prekrasno vino«, omenja, da je rasla "najlepša in najbolj plemenita trava«, ki je služila za pašo in vzrejo živine. Na območju Notranjske in Krasa je zaznal tudi veliko tovornikov s konji. V Zgornji Pivki se je veliko prebivalcev preživljalo z lesom, ki so ga vozili do morja, kjer so iz njega izdelovali »vse mogoče reči, potrebne za velike ladje«. V Vipavski dolini je poleg sadja zelo dobro uspevala vinska trta, vino, ki so ga pridelali, pa so dobičkonosno prodajali v »tuje dežele« (Valvasor 2009-13, 263-5).

Zaradi prehodne lege proti obalnim mestom so bile na Notranjskem in Krasu najbolj razširjene panoge, v katere se je vključevalo kmečko prebivalstvo, trgovina, tovorništvo in tihotapstvo. Ta tematika je v slovenskem zgodovinopisju najbolj obdelana s strani že obravnavanega Gestrina (1962; $1969 ; 1963 ; 1991)$. Iz obalnih mest proti notranjosti dežel Kranjske, Štajerske pa do Hrvaške sta potekala kmečka trgovina in tovorništvo s soljo, z vinom in oljem. V obratni smeri, v primorska mesta, je s kmečko trgovino potovalo »žito vseh vrst in moka, živina in mesni izdelki, sir in mast, kože in usnje in domače sukno ter platno, med in vosek, les in lesni izdelki ter drugi proizvodi domače dejavnosti« (Gestrin 1965, 42). Kmetje so tovorili lastno ali tuje žito, ki so ga kupovali na trgih ali tovorili in prodajali za zemljiške gospode v okviru tlačnega tovorništva. Voje je za logaško gospostvo ugotovil, da so najmočnejše kajžarske naselbine ležale prav ob poti LjubljanaTrst, kar nakazuje na prisotnost tovorništva. Vendar sklepa, da so kajžarji služili kot tovorniki - dninarji za gruntarje (večje kmete), ki so imeli svoje konje (Voje 1952-3, 661). 
Kot smo že omenili, sta v Vipavski dolini in na Krasu dobro uspevala tudi sadje in trta. O kmečki prodaji vina in sadja najdemo v objavljenih arhivskih virih več zapisanega kot v literaturi. Po zapisih v ljubljanskem tržnem redu iz leta 1571 so bili Vipavci (in Tržačani) med glavnimi prodajalci sadja na ljubljanskem trgu, svojega in tujega (Blaznik idr. 1980, 321). Istega leta predlagajo kranjski deželni stanovi, da se kmetom dovoli izvažati »vipavca, rebulo in druga laška sladka vina« iz dežele, saj zamenjava soli ni bila več docela prosta in je bilo to »do sedaj« v domeni tujcev (Žontar 1956-7, 78). Tudi Notranjska (Kras in Vipavska dolina), je bila po Valvasorju »blagoslovljena z zelo številnimi vini, ki so najboljša in povsod dobro znana [...] kajti vinska trta poganja roke in noge ne le s čašami, polnimi radosti, temveč tudi z dobrim upanjem na lep dobiček, ki ga bo prevažanje vina pripeljalo v mošnjiček« (Valvasor 2009-13, 255, 269). Pridelava vina in sadja ter njuna prodaja oz. menjava sta bili torej v novem veku pomembni in tradicionalni panogi, ki se ju je posluževalo kmečko prebivalstvo. Podobno lahko trdimo tudi za rejo živine, ki jo omenja Valvasor. To naj bi po besedah stanov leta 1531 kmetje redili »za delo in ne za zakol, saj se Kraševci preživljajo z rejo vlečnih volov (ziehochsen), ki imajo neužitno, trdo meso «, zato je bila izvzeta iz prepovedi izvoza iz dežele (Vilfan 1962, 139).

Kraški les je predstavljal blago, po katerem je povpraševanje prihajalo predvsem iz bližnjih mest, v času rasti v 18. stoletju pa še posebej Trsta. $\mathrm{V}$ omenjeno mesto so v 18. stoletju prihajali vaščani iz bližnjih kraških gospostev z lesom za kurjavo, gradnjo in trte (Gestrin 1965, 195; Panjek 2015b, 109-10). V notranjskih gozdovih so kmetje lovili tudi polhe. O lovu na polhe na Javorniku nam priča delo naravoslovca Franza Antona Steinberga iz leta 1758. Po njegovih besedah je polhovo krzno kmetom prinašalo velike dobičke:

Polšje kože prinašajo (na Javorniku) zelo dober profit; prodajajo jih krznarjem, ki jih izdelajo in šivajo v četverokotne tablice ter jih prodajajo $v$ velikih količinah [...] pošiljajo jih tudi v tuje dežele. Tukajšnji deželani jih poleg škorpijonovega olja in drugega drobnega blaga pošiljajo na Holandsko, od koder jih prodajajo celo $v$ Indijo. Ker so ti polhi zelo mastni, razpustijo kmetje njihovo mast, meso pa uživajo z zeljem in repo. (Baš 1981-3, 44)

Omenimo še tihotapstvo, ki je na tem območju doseglo svoj višek konec 16. stoletja, posluževali pa so se ga tako kmetje kot meščani. Še posebej se je razmahnilo po uveljavitvi tržaške prisilne poti in ukrepov, s katerimi je država uredila način plačevanja mitnin in predpisov na postajah 
v Ložu, na Planini, v Postojni in Podkraju v smeri proti Tržaškemu zalivu (Jadranskemu morju) in okrepila nadzor na poteh ter sejmih s cestnimi patruljami (iblajtarji - Überreiter). Kmečki trgovci so se ukrepom in nasilnim »iblajtarjem« upirali tako, da so se posluževali drugih, neobičajnih poti in se tako izogibali mitnic oz. so mitnice prehajali nasilno (Gestrin 1963, 78-9; 1965, 81-2; 1991, 277; Vilfan 1963, 2-4; Panjek 2002b, 162-3).

\subsection{Severna Istra}

Tržaška prisilna pot in tihotapstvo sta prizadela predvsem severno Istro (obmorska mesta Koper, Piran in Izola ter njihovo podeželje), ki so spadala pod Beneško republiko. Najhuje je bilo po mnenju Gestrina v Piranu. »Že od srede XV. stol. dalje je začela upadati v njem trgovina z lesom iz zaledja. Po letu 1500 [je še vedno morala] biti živahna le kmečka, tudi tihotapska trgovina, s katero je v Piran še vedno prihajalo žito in druga živila ter predmeti kmečke trgovine, a v notranjost je šla zlasti sol« (Gestrin 1963, 79). ' Avstrijski (habsburški) državni ukrepi so poleg Pirana močno prizadeli tudi Koper. Koprski podestat, lokalni predstavnik beneške države, sredi 17. stoletja omenja, kako je bila v preteklosti trgovina s habsburškim zaledjem živahna, zdaj pa zamira. Dnevno naj bi bili habsburški podložniki prihajali v Koper tudi s po 200 do 300 konji, »v zameno za istrske proizvode pa so prinašali žita, sir, volno, kože, železo, meso, zlasti goveje za potrebe mestnih mesnic, in razne izdelke, predvsem iz lesa, kot so sodi, kadi, čebri, škafi, omare ipd.« (Darovec 2004, 178).

Izvozno blago iz primorja v zaledje daje razumeti, da so bile na priobalnih beneških območjih razvite agrarne panoge, od katerih bi presežek pridelave kmetje lahko prodajali in prejemali dodaten vir dohodka. Med temi lahko naštejemo solinarstvo, ribištvo, oljarstvo in vinogradništvo. Vendar to domnevo le težje potrdimo, saj so $\mathrm{z}$ izjemo solinarstva ${ }^{\mathrm{I}}$ ostale naštete panoge za območje Istre $\mathrm{v}$ slovenskem zgodovinopisju slabše raziskane. Poleg tega se težava pojavi tudi pri prepoznavanju slojev prebivalstva v mestih in zaledju. Znotraj mest so poleg plemičev živeli populari, tj. mestno prebivalstvo nižjih slojev, med katere so sodili »solinarji, ladjedelci, mornarji, ribiči«, obrtniki, trgovci ter kmetje. Literatura jih največkrat navaja po imenu mesta ali obrti, ki jo opravljajo (na primer Pirančan,

9 O tihotapljenju koprske in piranske soli glej Žitko 1979; Bonin in Bonin 2015, 189206.

$10 \quad$ Glej na primer Pahor 1957; 1972; Vilfan 1962; 1963; Z. Bonin 2005; 2009; F. Bonin $2016 \mathrm{idr}$. 
Koprčan, solinar), in ne po sloju, ki mu pripadajo. Po pisanju Pahorja naj bi bilo v Kopru leta 1610 »izrazitih mestnih kmetov-popularov« mnogo, medtem ko naj bi jih bilo v Piranu zelo malo ali nič. ${ }^{\text {II }}$ Populare tako srečamo kot na primer poklicne solinarje, ki so kot zakupniki (koloni) obdelovali solne fonde meščanov in plemičev, ali kot lastnike (običajno zelo majhnega) dela solnih fondov (Pahor 1972, 32, 34, 57).

Poglejmo na kratko druge naštete panoge: ribištvo, vinogradništvo, oljarstvo in svilarstvo. Za piranske ribiče je znano, da so se ukvarjali s tihotapskim ribolovom in prodajo rib zunaj mesta (Pahor 1972, 61). Svilarstvo se je v severozahodni Istri pričelo razvijati ob koncu 17. stoletja, že prej pa sta bila prisotna tkalstvo in predilstvo. Leta 1763 sta dva podjetnika iz Kopra postavila predilnice svile, da bi s prodajo svile »v Avstrijske dežele« zagotovili delo in preživetje »tukajšnjemu ubogemu prebivalstvu«. Tako kot že na Goriškem, so bili tudi v obmorskih mestih aktualni predlogi s strani oblasti in posameznikov, da bi kmete usmerili v to donosno kulturo s sajenjem in z gojenjem murv za sviloprejo. Vendar so bili kmetje bolj naklonjeni tradicionalni istrski kmečki panogi, vinogradništvu (Darovec 2004, 244, 247, 280), katerega pridelek je bil eden glavnih izvoznih artiklov obmorskih mest.

\section{5 »Srednja Kranjska" in Dolenjska}

Ozrimo se še k zadnji tu obravnavani regiji, ki je bila v Valvasorjevem času deljena na dva dela, »Srednjo Kranjsko« in Dolenjsko, v današnjem času pa zajema vzhodni del Notranjske in Dolenjsko. Valvasor je tu zaznal veliko tovornikov, rokodelcev in trgovcev, ki so trgovali s platnom, z volmi in drugo živino, medom ter s polšjimi kožicami, pozabil pa ni omeniti niti »mogočnega gozda pri Snežniku« in prehvaliti »zdravega dolenjskega vina« (Valvasor 2009-13, 174, 188-92, 223). Posebej je omenil suhorobarsko obrt na območju Ribnice in Kočevja ter tovorništvo preko Cerknice proti Ljubljani in tudi proti morju. Tovorili niso samo po kopnem, ampak so tudi plavili po reki Savi, po kateri je tovor prihajal s Štajerske, z Dolenjske in s Hrvaške. Valvasor je na Dolenjskem, tako kot na Gorenjskem, zaznal tudi vasi, specializirane v neki dejavnosti. Na primer, omenja, da je v vasici Šmartno na štirih kmečkih hubah prebivalo »veliko tovornikov in vseh mogočih rokodelcev, zlasti 'veliko usnjarjev', ki so izdelovali črno usnje». Drugi primer je kraj Perišče, ki je ime dobil prav zaradi "peric, in žensk,

11 Po podatkih proveditorja iz leta 1626 naj bi večina koprskega prebivalstva živela od obdelave zemlje in pridelave soli, saj naj bi se vsak večer vračalo v mesto 1.500 ljudi (Darovec 2004, 175; Bonin 2005, 291; 2009, 100). 
ki belijo perilo in hodijo vsak teden $\mathrm{v}$ Ljubljano po umazano platno ter ga operejo. V vasi pa obelijo tudi veliko platnenega blaga in platnene preje« (Valvasor 2009-13, 180-1, 218-9).

Kot lahko vidimo iz Valvasorjevih opisov, je bilo obravnavno območje izredno dejavno $\mathrm{z}$ vidika obrti in tovorništva. Slednje je značilno predvsem za okolico Cerkniške doline, ki se povezuje s kraškim in notranjskim tovorništvom proti obmorskim mestom oz. zaledju in smo ga torej že obravnavali. Iz Novega mesta je namreč vodila prometnica proti Notranjski prek Rašice. Še pomembnejša prometna povezava je potekala ravno tako prek Novega mesta, in sicer iz Ljubljane proti hrvaškemu Zagrebu (Gestrin 1991, 105-6; Kosi 1998, 235), podložniki iz Bele Krajine in s Kočevskega pa so se vključevali v kmečko trgovino proti Reki (Gestrin 1972, 57). Kot omenja Valvasor, je trgovina potekala tudi po reki Savi, po kateri so plavili "vso robo iz Hrvaške, pa tudi del robe iz Štajerske in Dolenjske, proti Ljubljani« (Valvasor 2009-13, 158). Čolnarjenje »je bilo za večino čolnarjev postransko delo, ki so ga opravljali tedaj, ko niso bili vezani na delo na lastni kmetiji ali na zemljiškem gospostvu“ (Umek 1999, 276). Kmetje so torej dohodke od kmetijstva integrirali z dohodki od trgovine in čolnarjenja, v mejah višnjegorskega deželskega sodišča pa tudi od zakupa mitnic. V 16. in 17. stoletju so podeželske, "manjše mitnice praviloma zakupili kmečki ljudje«, v trgu Litija pa njeni prebivalci in sodniki (Golec 1995, 84).

Kot večina ostalih že opisanih regij je bil tudi današnji del Dolenjske $\mathrm{v}$ novem veku vinoroden okoliš. Tu so kmetje obdelovali vinograde bodisi kot podložniki bodisi kot zakupniki "gorskih vinogradov«, za katere so plačevali v naravi ali denarju. S širjenjem prebivalstva $\mathrm{v} 16$. stoletju srečamo še druge vrste podeželskega prebivalstva, kajžarje ter gostače, ki »stanujejo pri drugih kmetih ter trgujejo s platnom in drugim" (Vilfan 1952, 112; Granda 2005, 287). Območje Ribnice in Kočevja je še posebej poznano po suhorobarski obrti. Valvasor je za Kočevsko polje zapisal, da je tu

najti veliko lepih in velikih vasi; njihovi prebivalci so zelo bogaboječi in delovni. Vsi bodisi izdelujejo škatle, stružijo krožnike in sklede, izdelujejo žlice, rete in sita; tudi sicer delajo še vse mogoče izdelke iz lesa; svoje izdelke pa tudi raznašajo in razvažajo ne samo po vsej deželi, temveč tudi v sosednje dežele; pa svoje izdelke tudi precej daleč razpošiljajo. Prodajo tudi veliko polhovih kožic.

Tudi v Ribniški dolini je med prebivalci »veliko lončarjev in izdelovalcev ret, obročev, skled, krožnikov, škafov, in še vseh mogočih drugih posod 
iz lesa, pa strugarjev in mizarjev, ki vozijo in prodajajo svoje izdelke tako doma po deželi kot tudi v tujini« (2009-13, 218-9).

Večje zanimanje za te dejavnosti je zaznati v etnološki stroki, ki se je tej temi posvetila predvsem za obdobje 19. in 20 stoletja (Bras 1982; Drnovšek 2007; posamezni članki v Orel in Matičetov 1951 idr.), manj pa v zgodovinarski stroki. Kljub temu lahko orišemo nekatere prvine te dejavnosti že za obdobje zgodnjega novega veka. O trgovanju s suho robo priča že sejemska listina iz leta 1492, ko je cesar Friderik III. kočevskim in ribniškim podložnikom podelil privilegij, s katerim jim je dovolil trgovati »s svojo živino, platnom in drugim, kar sami vzgojijo in pridelajo « na Hrvaško in v druge dežele, s čimer je želel pomagati od turški vpadov uničenim ribniškim in kočevskim vasem. Ta privilegij je postal osnova tamkajšnjega krošnjarstva (Otorepec 1982, 83; Gradišnik 2012, 13). V 16. stoletju je bilo trgovanje z lesnimi izdelki že tako razširjeno, da ga je želela oblast obdavčiti. Sčasoma se je iz prvotne stroke razširilo več bolj specializiranih panog, kot so škafarstvo, žličarstvo, posodarstvo idr. (Trošt 1950-1, 36-7). Suhorobarji so svoje izdelke prodajali tudi kot krošnjarji, kot omenja že Valvasor, »tako po domači deželi kot tudi v tujini«. Lesno surovino so dajali prostrani snežniški in kočevski gozdovi. Kmetje pod Snežnikom so imeli v snežniških gozdovih služnostno pravico do merkantilnega lesa za prodajo in trgovanja z lesnimi proizvodi. Podobno kot so kočevski podložniki prejeli privilegij za prodajo lesnih izdelkov, so omenjeno pravico prejeli tudi kmetje loškega gospostva $\mathrm{z}$ namenom, da si ekonomsko opomorejo od turških vpadov v 16. stoletju (Kačičnik Gabrič 2004, 48-9). Med podložniki na gospostvu Snežnik mimogrede še omenimo, da zasledimo $\mathrm{v}$ 18. stoletju poleg tovornikov sezonske migrante, ki so "hodili poleti kosit, pozimi pa mlatit na Hrvatsko" (Valenčič 1981, 254). V gozdovih »Srednje Kranjske« so, tako kot v javorniških gozdovih, kmetje lovili tudi polhe, njihove kožice pa so "nosili v zelo oddaljene dežele kot na primer v Holandijo ter celo v Anglijo in Španijo « (Valvasor 2009-13, 211).

\section{Zaključek}

Za zaključek poskusimo preveriti, ali lahko v prispevku obravnavane gospodarske dejavnosti vzporedimo s shemo dejavnosti, prisotnih $\mathrm{v}$ integrirani kmečki ekonomiji, kot je bila predstavljena za zahodno Slovenijo v primerjavi z alpskim in zahodnoevropskim prostorom (Panjek 2014, 203; 2015a, 199). Na ta način bomo ugotovili, ali je omenjeno shemo mogoče razširiti tudi na osrednjo Slovenijo. 
Iz nabora gospodarskih dejavnosti, s katerimi se je novoveško kmečko prebivalstvo $\mathrm{v}$ večini slovenskih dežel ukvarjalo poleg kmetijstva, je mogoče ugotoviti precejšnjo raznovrstnost in gostoto panog. Te so sodile v vse tri ekonomske sektorje: primarnega, sekundarnega in terciarnega. Trdimo torej lahko, da je bila raznolikost in razširjenost dejavnosti v obravnavanih deželah precej velika. Težko bi sicer opredelili, katera od dejavnosti je bila najbolj razširjena oz. katera manj. Lahko pa rečemo, da je bila večina terciarnih dejavnosti (trgovina, tovorništvo, prevozništvo, tihotapstvo) zastopanih v vseh regijah. Nekaj je tudi takih, ki so lokalna specifika: na primer čipkarice na območju Idrije, ki so še danes svetovno prepoznavne, ali pa sviloprejstvo na Goriškem in v obalnih mestih, ki se je tam razvilo predvsem zaradi ugodnih pogojev za rast murvinih dreves. Na razširjenost določenih dejavnosti so tako vplivali tudi naravni pogoji, poleg že omenjenega svilogojstva omenimo še, recimo, solinarstvo v obmorskih mestih.

Primerjava zahodnega slovenskega prostora s celotnim alpskim prostorom in z zahodno Evropo je pokazala, da je bilo pri nas "prisotno in razširjeno veliko število različnih neagrarnih dejavnosti oz. kar večina izpričanih tipologij « (Panjek 2014, 203; 2017, 21-2). To izkazuje tudi naša analiza, ki poleg zahodnega prostora vključuje še osrednji slovenski prostor. Na podlagi ugotovljene številčnosti in raznovrstnosti gospodarskih panog torej lahko potrdimo, da je koncept integrirane kmečke ekonomije mogoče aplicirati v večjem delu slovenskih dežel v obdobju (zgodnjega) novega veka.

Nazadnje namenimo še nekaj besed slovenskemu zgodovinopisju. Pregled slovenske literature je pokazal, da v obdobju od zadnjih del F. Gestrina v devetdesetih letih prejšnjega stoletja do pojavitve koncepta integrirane kmečke ekonomije nismo bili deležni novih obsežnejših študij o kmečkem poseganju v neagrarne dejavnosti na Slovenskem. V vsakem primeru je mogoče zaključiti, da je še največ raziskovalne pozornosti slovenskih zgodovinarjev pritegnilo širše področje »kmečke trgovine«, ki je tudi konceptualno bolj dodelano in periodizirano do prehoda iz $16 . \mathrm{v} 17$. stoletje, in sicer zahvaljujoč Gestrinu. Tudi za Grafenauerja in druge avtorje iz prejšnjega stoletja lahko trdimo, da so ustvarili zelo dobro osnovo za nove raziskave, čeprav nekoliko neenako po posameznih področjih in z nekaterimi težavami, na katere so tudi že sami opozarjali.

\section{Literatura}

Baš, A. 1981-83. "Polšji lov na Slovenskem.« Traditiones, zbornik inštituta za slovensko narodopisje 10-2: 35-6o. 
Blaznik, P. 1959. »O podeželski obrti na loškem ozemlju do začetka 16. stoletja."Loški razgledi 6: 91-7.

Blaznik, P. 1966. »Prometne zveze preko Poljanske doline v freisinški dobi.« Loški razgledi 13: 37-43.

Blaznik, P. 1973. Škofja Loka in loško gospostvo (973-1803). Škofja Loka: Muzejsko društvo.

Blaznik, P., idr. 1970. Gospodarska in družbena zgodovina Slovencev. Zgodovina agrarnih panog, zv. 1. Ljubljana: Slovenska akademija znanosti in umetnosti in Državna založba Slovenije.

Blaznik, P., idr. 1980. Gospodarska in družbena zgodovina Slovencev. Zgodovina agrarnih panog, zv. 2. Ljubljana: Slovenska akademija znanosti in umetnosti in Državna založba Slovenije.

Bonin, F. 2016. Belo zlato krilatega leva: razvoj severnojadranskih solin vobdobju Beneške republike. Piran: Pomorski muzej.

Bonin, Z. 2005. "Koprske soline v poročilih beneških uradnikov.« Kronika: časopis za slovensko krajevno zgodovino 53 (3): 283-300.

Bonin, Z. 2009. »Koprske soline. "Studia Iustinopolitana: Revija Osrednje knjižnice Srečka Vilharja Koper, 2 (1): 95-120.

Bonin, Z., in F. Bonin. 2015. »Tihotapljenje koprske in piranske soli v obdobju beneške republike. $\mathrm{V}$ Upor, nasilje in preživetje, uredila F. Bianco in A. Panjek. Koper: Založba Univerze na Primorskem.

Bras, L. 1982. "Ribnica, njena suha roba in lončarstvo.«Kronika: časopis za slovensko krajevno zgodovino 30, (2): 144-151.

Čepič, Z., in D. Nećak. 1979. Zgodovina Slovencev. Ljubljana: Cankarjeva založba.

Darovec, D. 2004. Davki nam pijejo kri. Koper: Univerza na Primorskem, Znanstveno-raziskovalno središče; Zgodovinsko društvo za južno Primorsko.

Drnovšek, M. 2007. »Podoba kočevskih in belokranjskih krošnjarjev v očeh javnosti do začetka 2o. stoletja.« Kronika: časopis za slovensko krajevno zgodovino 55 (3): 387-404.

Gašperšič, J. 1959. „Gorenjsko železarstvo v XIV. in XV. stoletju.« Kronika: časopis za slovensko krajevno zgodovino 7 (1): 5-10.

Gašperšič, J. 1960. „Ferdinandejski rudarski red za fužine pod Jelovico.« Kronika: časopis za slovensko krajevno zgodovino 8 (3) 149-158.

Gestrin, F. 1962. »Gospodarstvo in družba na Slovenskem (Oris razvoja).« Zgodovinski časopis 16: 5-24. 
Gestrin, F. 1963. »Trgovina slovenskega zaledja s primorskimi mesti od XIII. do konca XVI. stoletja."Kronika: časopis za slovensko krajevno zgodovino 11 (2), 73-85.

Gestrin, F. 1965. Trgovina slovenskega zaledja s primorskimi mesti od 13. do konca 16. stoletja. Ljubljana: Slovenska akademija znanosti in umetnosti.

Gestrin, F. 1969. „Oris gospodarstva na Slovenskem v obdobju zgodnjega kapitalizma.« Kronika: časopis za slovensko krajevno zgodovino 17 (1): 1-8.

Gestrin, F. 1972. Mitninske knjige 16. in 17. stoletja na Slovenskem. Ljubljana: Slovenska akademija znanosti in umetnosti.

Gestrin, F. 1973a. »Boj za podeželsko trgovino med mestom in vasjo od konca 15. do srede 17. stoletja."Jugoslovenski istorijski časopis 12: 72-80.

Gestrin, F. 1973b. »Kmečka trgovina kot ozadje kmečkih uporov.« Situla 13: $45-67$.

Gestrin, F. 1973c. »Kmečka trgovina in upori.« Kronika: časopis za slovensko krajevno zgodovino 21 (1): 1-4.

Gestrin, F. 1973d. »Trgovina in kmečki upori na Slovenskem in Hrvatskem v XVI. stoletju.«Zgodovinski časopis 26 (3-4): 207-17.

Gestrin, F. 1982a. "Marginalije k Valenčičevi razpravi o tovorništvu na Kranjskem.«Zgodovinski časopis 36 (4): 347-54.

Gestrin, F. 1982b. »Nekaj pogledov na gospodarsko zgodovino v slovenskem.« Zgodovinski časopis 36 (3): 205-11.

Gestrin, F. 1991. Slovenske dežele in zgodnji kapitalizem. Ljubljana: Slovenska matica.

Golec, B. 1995. »Trgovski promet na širšem območju Višnje gore do konca 18. stoletja v luči deželskosodnih in mestnih mitnic.«Zgodovinski časopis 49 (1): 75-98.

Gomiršek, T. 2007. Rebula nekoč in danes. Nova Gorica, Goriški muzej.

Gradišnik, M. 2012. »Obdobje petnajstega in šestnajstega stoletja - med novo vero, božjo šibo in krošnjarjenjem.«V Križem svajt so se podal pa sujo ruobo ponujal: pregled ribniškega krošnjarjenja od patenta leta 1492 do danes, uredili M. Gradišnik idr. Ribnica: JZ Rokodelski center - zavod za rokodelstvo, muzejsko in galerijsko dejavnost: 8-15.

Grafenauer, B. 1962. Kmečki upori na Slovenskem. Ljubljana: Državna založba Slovenije.

Grafenauer, B. 1973. »Položaj kmeta in kmečki upori od 15. do 19. stoletja.« Mednarodni kulturnozgodovinski simpozij Modinci, Maribor 1973.

Grafenauer, B. 1974. Boj za staro pravdo v 15. in 16. stoletju na Slovenskem: slovenski kmečki upor 1515 in hrvaško-slovenski kmečki upor 1572/73 s pose- 
bnim ozirom na razvoj programa slovenskih puntarjev med 1473 in 1573. Ljubljana: Državna založba Slovenije.

Granda, S. 2005. »K zgodovini cvička.«V Ad fontes: Otorepčev zbornik, uredila D. Mihelič, 281-301. Ljubljana: Založba ZRC, ZRC SAZU.

Hodnik, M. 1995a. »Kraja živosrebrne rude in kaznovanje tatov iz loškega gospostva." Loški razgledi 42 (1): 31-7.

Hodnik, M. 1995b. »Tihotapci živosrebrove rude v 18. stoletju.« Idrijski razgledi 40: 22-27.

Kačičnik Gabrič, A. 2004. O kmečkih dolgovih nekoliko drugače: problem servitutnih pravic na posestvu Snežnik. Ljubljana: Zveza zgodovinskih društev Slovenije; Arhiv Republike Slovenije.

Kavčič, I. 2010. »Petsto dvajset let vezi med Idrijo in Škofjo Loko.« Loški razgledi 57 (1): 135-47.

Kolenc, P. 2011. »Med glažutarji na robu Trnovskega gozda: razvoj steklarske obrti med Gorenjo Trebušo, Lazno in Lokvami v letih od 1722 do 1825/30.« Goriški letnik: zbornik Goriškega muzeja 35: 95-125.

Kolenc, P. 2012 »'V osrčju brezmejnega gozda'. Raba, izkoriščanje in gospodarjenje s Trnovskim gozdom od naselitve do konca 19. stoletja."Kronika: časopis za slovensko krajevno zgodovino 6o (2): 203-20.

Kosi, M. 1998. Potujoči srednji vek: cesta, popotnik in promet na Slovenskem med antiko in 16. stoletjem. Ljubljana: ZRC SAZU, Založba ZRC.

Mihelič, D. 1999. "Zgodovina sodarske obrti na Slovenskem."V Vilfanov zbornik: pravo, zgodovina, narod, uredila V. Rajšp in E. Bruckmüller, 65979. Ljubljana: ZRC SAZU, Založba ZRC.

Mohorič, I. 1954. »Zgodovina plavža v Železnikih.«Kronika: časopis za slovensko krajevno zgodovino 2 (2): 95-10o.

Mohorič, I. 1955. "Zgodovina fužin ob Bistrici pri Kamniku.«Kronika: časopis za slovensko krajevno zgodovino 3 (1-2): 25-32.

Mohorič, I. 1969. Dva tisoč let železarstva na Gorenjskem. I. del. Ljubljana: Mladinska knjiga.

Orel, B., in M. Matičetov, ur. 1951. Slovenski etnograf3-4. Ljubljana: Etnografski muzej.

Otorepec, B. 1982. »Doneski k zgodovini Ribnice in okolice v srednjem veku.« Kronika: časopis za slovensko krajevno zgodovino 30 (2): 79-87.

Pahor, M. 1957. »Statuti Izole, Kopra in Pirana ter istrski zakoni o solarjih, solarnah in tihotapcih. "Kronika: časopis za slovensko krajevno zgodovino 5 (3): 123-34. 
Pahor, M. 1972. Socialni boji v občini Piran od XV. do XVIII. stoletja. Ljubljana: Mladinska knjiga; Piran: Pomorski muzej »Sergej Mašera«.

Panjek, A. 2002a. »O gospodarskem pomenu meje za prebivalstvo Vzhodnih Alp s posebnim ozirom na zgornje Posočje: (16 -18. stoletje).« V Soški razgovori I: zbornik za domoznanstvo Zgodovinske sekcije KD Golobar, uredil J. Kunaver, 215-26. Bovec: Zgodovinska sekcija Kulturnega društva Golobar.

Panjek, A. 2002b. Terra di confine: agricolture e traffici tra le Alpi e l'Adriatico: la contea di Gorizia nel Seicento. Mariano del Friuli (Go): Edizioni della Laguna.

Panjek, A. 2011. "Not Demesne but Money: Lord and Peasant Economies in Early Modern Western Slovenia." Agricultural History Review 59 (2): 293-311.

Panjek, A. 2014. »Integrirana ruralna ekonomija v zahodnem slovenskem prostoru v zgodnjem novem veku. V Vizija raziskav slovenske gospodarske in družbene zgodovine, uredila D. Mihelič, 199-205. Ljubljana: Založba ZRC.

Panjek, A. 2015a. »Integrated Peasant Economy in Early Modern Slovenia: The Institutional Framework and the Concept. "Histoire des Alpes 20: 187-207.

Panjek, A. 2015b. Vzhodno od Benetk, slovenski obmejni prostor: gospodarstvo, družba, prebivalstvo in naravni viri v zgodnjem novem veku. Koper: Univerzitetna založba Annales.

Panjek, A. 2017. »The Integrated Peasant Economy as a Concept in Progress «. $\mathrm{V}$ Integrated Peasant Economy in a Comparative Perspective: Alps, Scandinavia and Beyond, uredili A. Panjek, J. Larsson in L. Mocarelli, 1149. Koper: Založba Univerze na Primorskem.

Rajšp, V. 1994. »Obsoška cesta v prometni politiki avstrijske države.« Kronika: časopis za slovensko krajevno zgodovino 42 (1) 1994: 46-51.

Šmitek, J. 1989. »Fužinsko tovorništvo (Mitnice v Bači 1536). "Loški razgledi 36 (1): $23-31$.

Šorn, J. 1984. Začetki industrije na Slovenskem. Maribor: Založba obzorja.

Terpin, M. 2007. »Marina Melhiorca - pomočnica tatov: proces proti tolpi tatov in tihotapcev 1729-1731. "Idrijski razgledi 52 (2): 84-99.

Trošt, J. 1950-51. »Ribniška suha roba v lesni domači obrti.« Slovenski etnograf 3-4: 28-67.

Umek, E. 1999. »Promet po Savi in Ljubljanici.«V Gestrinov zbornik uredila D. Mihelič, 271-8. Ljubljana: ZRC (ZRC SAZU).

Valenčič, V. 1981. »Tovorništvo na Kranjskem.« Zgodovinski časopis 35 (3): 243-77. 
Valvasor, Janez V. 2009-13 . Čast in slava vojvodine Kranjske. Faksimile - prevod. Izvirnik iz leta 1689. Ljubljana: Zavod Dežela Kranjska.

Verbič, M. 1952-53. »Idrijski delavec v 16. stoletju.«Zgodovinski časopis, Kosov zbornik, 6-7: 531-51.

Verbič, M. 1963. »Gospodarski stiki Loke z Idrijo v 16. in 17. stoletju.«Loški razgledi 10 (1): 97-103.

Verbič, M. 1969. „O začetkih slovenskega čipkarstva s posebnim ozirom na Idrijo.«Kronika: časopis za slovensko krajevno zgodovino 17 (3): 157-6o.

Vilfan, S. 1952. »Od vinskega hrama do bajte: (prispevki k zgodovini bajtarstva in gostaštva v dolenjskih vinogradih).« Slovenski etnograf 5: 107-42.

Vilfan, S. 1962. »K zgodovini kmečkega kupčevanja s soljo: (gospodarsko-pravne podlage povesti o Martinu Krpanu).« Kronika: časopis za slovensko krajevno zgodovino 10 (3): 129-44.

Vilfan, S. 1963. „K zgodovini kmečkega kupčevanja s soljo: (gospodarsko-pravne podlage povesti o Martinu Krpanu).« Kronika: časopis za slovensko krajevno zgodovino. 11 (1): 1-12.

Voje, I. 1952-1953. »Kajžarstvo v logaškem gospostvu.« Zgodovinski časopis, Kosov zbornik, 6-7: 650-62.

Vrhovec, I. 1886. Ljubljanski meščanje v minulih stoletjih: kulturhistorične študije zajete iz ljubljanskega mestnega arhiva. Ljubljana: Matica Slovenska.

Zwitter, F. 1929. »Starejša kranjska mesta in meščanstvo.« Doktorska disertacija, Leonova družba.

Žitko, S. 1979. »Solno tihotapstvo na območju piranskih, koprskih in miljskih solin v času Beneške republike."Slovensko morje in zaledje: zbornik za humanistične, družboslovne in naravoslovne raziskave 2-3: 79-95.

Žontar, J. 1956. »Platnarstvo in sitarstvo v loškem gospostvu v 18. stoletju.« Loški razgledi 3: 89-102.

Žontar, J. 1956-57. »Nastanek, gospodarska in družbena problematika policijskih redov prve polovice 16. stoletja za dolnjeavstrijske dežele s posebnim ozirom na slovenske pokrajine.«Zgodovinski časopis 10-11: 32-121.

Žontar, J. 1957. Svilogojstvo in svilarstvo na Slovenskem od 16. do 20. stoletja. Ljubljana: Slovenska akademija znanosti in umetnosti.

Žontar, J. 1982. Zgodovina mesta Kranja. Ljubljana: Muzejsko društvo za Slovenijo. 